\title{
O QUE LEVA ALGUÉM A QUERER SER PROFESSOR? Em blogs e no Facebook, narrativas de professores em formação inicial contam sobre as escolhas pela profissão

\author{
Luciane Mulazani dos Santos, UDESC \\ lucianemulazani@gmail.com
}

Resumo: Este trabalho apresenta uma experiência sobre a utilização de blogs e de um grupo do Facebook em disciplinas curriculares de um curso de licenciatura em Matemática. Mostra como as narrativas registradas nesses espaços digitais pelos alunos das disciplinas de Estágio Curricular Supervisionado II e Didática da Matemática despertaram discussões acerca das escolhas pela profissão de professor. A utilização dos recursos do Facebook possibilitou uma reflexão crítica a partir dos comentários feitos para uma postagem realizada em um blog por um dos alunos que acompanhavam as aulas de matemática em uma escola da educação básica. No presente texto, faz-se também uma reflexão sobre o trabalho com narrativas na formação inicial de professores.

Palavras-chave: formação inicial de professores, blogs, Facebook, narrativas.

\section{WHAT TAKES SOMEONE WANTS TO BE A TEACHER? In blogs and on Facebook, narratives of teachers in initial training rely on the choices by profession}

\begin{abstract}
This paper presents an experience on the use of blogs and a Facebook group in curricular subjects a degree in Mathematics. Shows how the narratives recorded in these digital spaces by students aroused discussions about the choices for the teaching profession. The use of Facebook features enabled critical reflection from the comments made to a post made on a blog by one of the students who accompanied the math classes in a school of basic education. In this paper, it is also a reflection on the work with narratives in teacher education.
\end{abstract}

Keywords: initial teacher training, blogs, Facebook, narratives. 


\section{Introdução}

Para apresentar este artigo, uso da liberdade ao utilizar a narrativa em primeira pessoa, como que contando uma história, para trazer para meu texto uma característica do estudo feito e aqui discutido, o qual guiou-se pelo olhar para narrativas de alunos de um curso de formação inicial de professores. Sou professora universitária de um curso de Licenciatura em Matemática e ministro disciplinas relacionadas com a formação inicial de professores. Em minhas propostas de ensino, procuro desenvolver atividades com os alunos que os preparem para o exercício da profissão de professor e que os façam refletir sobre a prática docente. Como pesquisadora, trabalho estudando a utilização das Tecnologias de Informação e Comunicação (TICs) em processos de ensino e aprendizagem. No planejamento das atividades para o primeiro semestre de 2013, incluí nos planos de ensino das minhas três disciplinas algumas propostas resultantes dos resultados de meu projeto de pesquisa em TICs. O meus objetivos, com isso, foi aliar teoria com prática para acompanhar e avaliar as atividades dos meus alunos de uma maneira diferenciada, ao mesmo tempo tempo em que os inseria no contexto da utilização das TICs na prática docente. Assim, na disciplina de Estágio Curricular Supervisionado II, momento em que os alunos observam aulas ministradas por professores de Matemática na Educação Básica, utilizei os blogs como diários virtuais reflexivos e portfólios digitais onde os alunos registraram seus rastros de experiências advindos das visitas e observações em escolas de Educação Básica. Na disciplina Laboratório de Matemática IV, propus aos alunos a utilização da plataforma gratuita Chamilo, um Sistema de Gerenciamento de Aprendizagem (LMS - Learning Managment System) para a realização de atividades em que eles se colocaram como professores autores e gestores de cursos online de conteúdos matemáticos de Ensino Médio experimentando, assim, os movimentos da educação a distância. Já na disciplina Didática da Matemática, utilizei um grupo privado criado na rede social Facebook como apoio às discussões e aprendizagens presenciais, onde discutimos conteúdos estudados na disciplina, compartilhamos notícias e ideias relacionadas com os assuntos estudados, tratamos da rotina e da avaliação das atividades da disciplina e compartilhamos experiências acerca de temas transversais ao plano de ensino. Assim, ao longo do primeiro semestre de 2013, orientei e acompanhei as atividades realizadas pelos alunos das três disciplinas observando como, em cada uma das turmas, eles transitaram pelas três soluções tecnológicas utilizadas com a proposta de ensinar e aprender: o blog, o sistema de gerenciamento de aprendizagem e a rede social. Por conta das características desses ambientes, percebi, entre outras coisas, interessantes relações estabelecidas entre as narrativas publicadas nos blogs e no Facebook, espaços onde os usuários inserem conteúdos de forma compartilhada expressando ideias e opiniões promovendo ambientes férteis para discussão. Separei uma narrativa de um aluno da disciplina de Estágio postada em seu blog e a publiquei no grupo da disciplina de Didática da Matemática no Facebook com o objetivo de problematizar a seguinte questão: "o que leva alguém a querer ser professor?". Neste texto, apresento as narrativas dos alunos referentes a esta questão registradas nos ambientes tecnológicos citados e algumas reflexões acerca do tornar-se professor.

\section{Redes sociais na internet, comunicação e educação}

Experimentamos, em sala de aula e também fora dela, mudanças nos processos comunicativos com nossos alunos, reflexos da transformação social em tempos de comunicação digital. Estamos crescendo em número e nos organizando cada vez mais, mudando paradigmas, motivados pelas novas possibilidades de comunicação. As redes sociais da internet têm um interessante papel neste contexto. Assim como é importante 
discutir a transformação da sociedade e a produção de conhecimentos, professores dos diferentes níveis de ensino devem estar atentos às discussões em torno do ideal por processos de ensino e aprendizagem cada vez mais eficazes como, por exemplo, aquelas que tratam da utilização dos recursos da TIC na educação. É nesse contexto que se inserem as redes sociais e os blogs da internet como ferramentas e soluções que podem ser implementadas tanto dentro quanto fora de sala de aula, servindo de apoio às atividades de ensino e aprendizagem. A utilização dos blogs e das redes sociais possibilita ações espontâneas que obedecem uma nova lógica quanto às suas configurações e às formas de sua ação social que podem ser aproveitadas de maneira eficaz e criativa na Educação. São transformadas antigas relações, o trabalho em rede suscita debates, promove a discussão e a colaboração entre os usuários. Tudo de uma forma bastante ágil, de fácil utilização e prática que movimenta diversos tipos de saberes muito rapidamente e de forma abrangente. Os blogs e as redes sociais são ferramentas utilizadas pela internet, usando plataformas online para produção de conteúdos sobre os mais diferentes temas e com finalidades diversas. Sua principal característica é o trabalho em formato descentralizado, não hierárquico e de livre expressão. Apresentam design e modus operandi que dão às atividades de seus usuários - na forma de textos, sons, imagens - um caráter de autonomia, de colaboração espontânea e de compartilhamento. Muitas destas ferramentas são gratuitas, o que as torna soluções que podem ser utilizadas por um número muito grande de pessoas ampliando, assim, sua atuação como facilitadora do processo comunicativo em redes colaborativas. A diferença principal entre ambas é a forma como os conteúdos são publicados e organizados. O blog, também chamado de weblog, é uma página da internet formada por textos organizados cronologicamente que podem ser comentados pelos leitores. Em seu conteúdo, assemelha-se a um jornal ou a um diário que segue uma linha do tempo para apresentar um registro depois do outro. É um veículo onde o blogueiro - o autor de um blog - pode expressar aquilo que pensa sobre os mais diversos assuntos e também escrever sobre o seu cotidiano, usando o espaço como um diário virtual. Já na rede social Facebook - a utilizada nessa pesquisa - os usuários se unem, de forma pública ou privada, pela publicação e compartilhamento de textos, imagens, aúdios e vídeos sobre os mais diferentes assuntos. Neste espaço digital, podem ser criadas páginas de grupos de interesse comum ou de assuntos específicos, tornandose assim, fórum de discussão sobre esses temas. Seu uso é bastante intuitivo, amigável e de fácil compreensão, o que contribuiu para sua popularização. Tanto os blogs quanto o Facebook são espaços onde se podem trabalhar a teoria e a prática em educação de maneiras inovadoras e significativas.

\section{Vivências e narrativas de professores em formação inicial}

Eu sempre quis ser professora. E professora de Matemática. Sempre. Quando estava em tempos de decidir a opção do vestibular, contei para a família toda, para os meus amigos de escola e para meus professores que queria prestar vestibular para Matemática. Da família, ouvi que isso seria um desperdício, previsões pessimistas sobre o que eu iria fazer da vida sendo professora de Matemática; lembro-me de uma amiga de minha mãe, professora de Matemática já há muito tempo, me dizendo para eu esquecer essa bobagem e escolher uma profissão que prestasse. Dos amigos da escola, não senti muito espanto pois eu sempre fui uma excelente aluna de Matemática e, para eles, aquela era uma escolha natural; eles só não entendiam muito porque eu queria fazer o trabalho chato de ser uma professora. Já dos meus professores da escola, recebi certo desencorajamento vindo da uma proposta alternativa: se você é tão boa aluna em 
Matemática e gosta tanto de ciências exatas, escolhe uma Engenharia e não ser professora.

As incompreensões acerca do tornar-se professora não acontecem somente comigo. Há tempos eu ouço os alunos do curso de licenciatura contarem sobre os comentários que ouvem na família, no grupo de amigos e nos estágios que fazem nas escolas sobre os porquês de terem escolhido estudar para serem professores. Em grande parte das vezes, os comentários vêm junto com um desincentivo e uma crítica negativa a respeito da profissão de professor. Os motivos são variados e são bem conhecidos de todos nós, tratando principalmente da desvalorização da profissão e das más condições de trabalho. Alguns estagiários, por exemplo, vêm sendo desencorajados pelos próprios professores que atuam nas escolas onde eles fazem os estágios de observação e regência. Essa é uma questão que me preocupa muito, a mim e a muitos de meus colegas de trabalho. Isso faz com que trabalhemos em torno da defesa da profissão, problematizando o assunto com nossos alunos sempre que possível.

No primeiro semestre de 2013, novamente me deparei com essa situação, desta vez declarada na narrativa escrita por um aluno da disciplina de Estágio Curricular II no blog criado por ele para registro das atividades de suas vivências no estágio. Um trecho do texto de Souza Neto (2005) que li há algum tempo me voltou à reflexão para compor a discussão que levei para o grupo do Facebook da disciplina de Didática da Matemática sobre a narrativa do aluno da disciplina de Estágio, discussão essa que será apresentada na sequência desse texto.

Por que um dia nos tornamos professores? Vamos tentar responder isso voltando ao círculo inicial, para perguntar qual o papel social dessa profissão que é ensinar aos outros aquilo que eles ainda não sabem, ou ainda não sabem que sabem, ou apenas sabem de modo assistemático ou que temos de aprender com eles o que sabem? Ou, dizendo de outro modo, qual o lugar social dessa profissão responsável por educar os outros para serem, saberem e fazerem de maneira universal na diversidade certos procedimentos comuns a toda a humanidade? Ou ainda, para fazer a mesma indagação de outra maneira, qual a importância dessa profissão para a sociedade em que vivo e para aquelas que virão? (SOUZA NETO, 2005, p. 255)

Lendo os blogs de estágio semanalmente, um dia me deparei com a narrativa de um de meus alunos sobre uma pergunta que uma estudante do Ensino Fundamental lhe fez durante um dia de estágio na escola. A transcrição segue abaixo.

domingo, 7 de abril de 2013

\section{Sorriso falso}

P.A. fazendo estágio e durante a aula recebe a seguinte pergunta aleatória de uma aluna: "só uma perguntinha 'sor', o que leva uma pessoa a querer ser professor?"

Eu não disse nada, apenas tive um sorriso falso e continuei a fazer o que é pertinente ao relatório. Mas o que dizer nesta hora? E o pior de tudo, parar e pensar realmente no que ela disse.

Incomodada com a pergunta, preocupada com a repercução de situações como estas entre os meus alunos e percebendo a necessidade de problematizar essa questão não somente com os alunos da turma de Estágio - o que foi feito por meio dos 
comentários nos blogs da turma - mas também com os alunos que cursavam Didática da Matemática, levei a discussão para o grupo do Facebook que utilizamos para as atividades da disciplina, reproduzida abaixo:

\section{Luciane Mulazani Dos Santos}

"só uma perguntinha 'sor', o que leva uma pessoa a querer ser professor?" (pergunta de uma aluna do Ensino Fundamental ao estagiário do curso de Matemática)

Nem sei direito o que eu sinto ao imaginar o sentimento dessa aluna em relação à profissão de professor...

Vocês podem me ajudar a entender o que tem por trás do comentário dessa aluna? (que acaba sendo pensamento de muitos alunos)

\section{Curtir · Seguir (desfazer) publicação $\cdot 9$ de abril às 02:14}

\section{Visualizado por 13}

Aluna 1 Olha, professora, tenho que te dizer que também já ouvi essa pergunta no estágio, feita por alunos E por professores.

\section{9 de abril às 02:19 . Curtir}

Aluna 2 Hoje mesmo no meu estágio, a professora foi me apresentar para a nova turma, e eu ouvi uma aluna comentando com sua colega "meu Deus, o que leva alguém a fazer matemática, e pior ainda, ser professora disso?". Lamentável. Depois de observar a aula, percebi que ninguém levou a aula a sério alegando que a matemática da escola não era importante, nem pro ENEM, já que agora a correção das provas está uma vergonha - palavras de um aluno. Depois me dei conta que tal indivíduo ainda não teria amadurecido o suficiente, já que ele e sua turminha brincavam de quem era mãe/pai de quem, enquanto a professora explicava o comprimento da circunferência.

\section{9 de abril às 02:20 - Curtir}

Aluna 2 idem Aluna 1, frases do tipo foram colocadas na minha recepção na sala dos professores.

\section{9 de abril às 02:21 . Curtir}

Luciane Mulazani Dos Santos pois então, como não estou conseguindo dormir, pensei agora numa coisa que quero perguntar para vocês: para qual profissão vocês olham e pensam: "o que leva uma pessoa a querer ser isso?" Tem alguma?

\section{9 de abril às 02:30 via celular · Curtir}

Aluna 3 pior não é nem os alunos de sétima série perguntando algo do tipo pra nós, é escutar isso de alguém com 20 e poucos anos de idade, que pra chegar onde chegou precisou passar por 30 professores e que deveria ter maturidade pra reconhecer a nossa profissão.

\section{9 de abril às 04:22 · Curtir · 1}




\begin{abstract}
Aluna 3 acabei de voltar do pronto atendimento e pensei "não conseguiria ser médica", mas sei que há motivos (bons motivos, até \$) e valorizo a profissão. pois ainda bem que se eu não tenho estômago pra isso, alguém tem. e é isso. acho que condições física, psicológicas, e até financeiras nos fazem escolher nossas profissões, e temos que respeitar todas elas.
\end{abstract}

\title{
9 de abril às 04:28 - Curtir
}

Aluna 4 Essa é uma pergunta que as professoras do colégio me fizeram: "Você é tão nova, vai fazer outra coisa! O que te levou a escolher essa profissão?" Mas acho que elas falaram isso porque estavam perto de se aposentar, talvez seja uma depressão no final da carreira docente. Mas, uma vez, perguntei a um senhor que estava fazendo concurso para ser coveiro, porque ele não prestou concurso para uma área melhor. Ele respondeu que gente morta incomoda menos do que gente viva e não reclama do serviço dele. Tudo é questão de ponto de vista!

\section{9 de abril às $18: 10 \cdot$ Curtir · 1}

Aluna 1 hahahaha Esse coveiro devia ser uma pessoa só um pouquinho rabugenta! Eu também não poderia ser médica, porque não tenho estômago para isso e, como disse hoje de manhã, não consigo me imaginar fazendo nenhum tipo de serviço burocrático ou qualquer coisa mecânica e repetitiva, onde eu só lidasse com máquinas, papéis e computadores. Gosto de estar no meio de gente, de fazer um trabalho que atinja outras pessoas.

\section{9 de abril às 20:09 · Curtir · 1}

Aluna 5 Também ouvi esses comentários hoje no meu estágio, concordo com a Aluna 1, eu não poderia ser médica, não poderia ser nenhum tipo de atleta....odeio fazer exercícios físicos, e nem trabalhar em lugares silenciosos, como biblioteca, museu, indústria...sou muito faladeira. Agora a profissão que realmente eu nunca, mas nunca seria, é ser legista (faz as necrópsias).

\section{0 de abril às 01:07 · Curtir · 1}

Aluna 6 Essa foi uma pergunta que uma professora me fez no estágio 2, e também muitas outras pessoas já fizeram está pergunta. Essa pergunta acontece por que os professores só reclamam de tudo, nada está bom para eles, acham que o salário que ganham é muito pouco, entre outros motivos. Em certas partes até concordo com eles, mas quando eles escolheram ser professores já sabiam das condições de ser um professor, então acho errado eles criticarem quem quer ser professor, pois ser professor é muito bom, saber que você pode transmitir seu conhecimento, aprender também muitas coisas com os alunos, ter a liberdade de ensinar de maneiras diferentes para os seus alunos. E também escolhi está profissão porque não gosto de trabalhar em lugares fechados, não gosto de ficar atendendo telefone e nem de ficar o dia inteiro na frente do computador, etc. E porque será que os professores que reclamam tanto, não escolhem outra profissão ou continuam seus estudos para alcançar os seus objetivos em vez de ficarem só reclamando?

\section{0 de abril às 17:01 · Curtir · 1}

Aluna 7 No primeiro estágio que realizei, uma professora me falou que eu ainda estava estagiando pois não havia ministrado aulas, era por isso que não havia desistido. E também ouvi muitos professores falando que estava fazendo a escolha errada. Em vez destes professores valorizarem a sua própria profissão, ainda falam mal dela. E é por isto que talvez os alunos não gostem da profissão de ser professor, pois já que os seus professores só falam mal dela, e não há um nenhum incentivo. 
Aluna 8 Isso é o que escuto em todos os estágios... você chega para ser apresentado na escola, tanto para os professores e quanto para os alunos e o que você ouve é: "nossa tanto curso para fazer, e vai fazer bem para ser professora e ainda de matemática??"... e o que eu faço é dar uma risadinha sem graça...

\section{1 de abril às 22:23 - Curtir}

Aluna 9 é o primeiro questionamento que fazem: nossa, vc faz matemática? acho que essas pessoas não veem a dimensão do ser professora e que sem o professor nem elas mesmas estariam formadas ou cursando um curso ou algo do tipo! por mim, o que me levou mais a optar pela licenciatura, foi o gosto que uma professora minha tinha ao dar aula!

\section{5 de abril às 01:09 - Curtir}

De acordo com Roldão (1995), as narrativas podem ser usadas como instrumentos educativos, constituindo artefatos culturais que podem atuar nos processos de aprendizagem e também na organização do pensamento e da realidade. Segundo Reis (2008):

A análise e discussão destas narrativas permitem que os alunos aprendam de forma ativa, desenvolvendo capacidades analíticas e de tomada de decisão, interiorizando conhecimentos, aprendendo a lidar com situações complexas e controversas da vida real, desenvolvendo capacidades comunicacionais, reforçando a sua auto-confiança e, frequentemente, trabalhando colaborativamente. (REIS, 2008)

Para Chené (1988), é bastante pertinente o uso das narrativas para compreender e atuar no processo de formação inicial dos professores, pois

Teoricamente, a narrativa leva à compreensão do percurso da formação. Na prática, permite igualmente que o formador encontre o seu projeto de ser e se formar através da fragilidade das figuras que toma no tempo da narração, e se reapropria do julgamento de competência que faz sobre si próprio (CHENE, 1988, p.96).

Isso permite a criação de um espaço comunicativo comum a professor formador e alunos em formação inicial onde ambos compartilham aspectos relacionados ao fazerse professor. As narrativas dos alunos na conversa via grupo do Facebook mostra como cada um deles de coloca a respeito da vivência de outro colega. Mostra como as experiências, nesse caso, convergem para uma mesma situação de questionamento acerca da profissão que escolheram e sobre a qual estão em processo de formação inicial.

A narrativa constitui um processo de interacção, independentemente da forma como é utilizada. [...] Através da leitura e análise destas narrativas [os alunos] têm oportunidade de reflectir e de aprender sobre os processos de aprendizagem, os impactos de determinadas experiências educativas, os problemas e as dificuldades que os professores enfrentam ao longo da sua carreira, as estratégias que utilizam na tentativa de os superar, a importância de práticas colaborativas e muitos outros aspectos da vida de professores e alunos. (REIS, 2008, p. 5) 
A pesquisa de Reis (2008) apresenta exemplos semelhantes de narrativas que tratam da formação e das escolhas de futuros professores, o que mostra ser esse um tema recorrente nos cursos de licenciatura. Moraes (2004) discute justificativas para a utilização de narrativas em pesquisas do domínio das ciências da educação e da formação. Após sistematizar o pensamento de diversos autores, conclui que

\begin{abstract}
A narrativa tem sido utilizada, na pesquisa qualitativa, como um instrumento de coleta de dados, com o mérito de ser considerado também um trabalho formativo, porque pode permitir a organização das experiências humanas: ao mesmo tempo em que o sujeito organiza as suas ideias para o relato- quer escrito, quer oral - também reconstrói sua experiência de forma reflexiva e, com isso, acaba fazendo uma autoanálise que lhe pode proporcionar novas bases de compreensão de sua própria prática. Por isso, o uso de narrativas como procedimento de pesquisa pode servir, ao mesmo tempo, como alternativa de investigação e de formação. [...] Ouvir as narrativas das histórias que compõem a vida dos docentes é oportunizar momentos de reflexão, descortinando alternativas que podem ajudar na sua formação e na de outros professores. (MORAES, 2004)
\end{abstract}

Estendo as considerações a respeito da voz dos professores atuantes para a voz dos professores em formação para considerar que os alunos, em seu processo de formação inicial como professores, ao discutirem suas próprias narrativas sobre o que ouvem a respeito da profissão refletem sobre si e sobre suas escolhas.

Além disso, as pesquisas pautadas nas narrativas de formação podem permitir a superação de uma prática, tradicionalmente exercida por pesquisadores adeptos do paradigma positivista de compreender a ciência, os quais teorizam sobre o professor e sobre a sua prática, sem, no entanto, admitir ser possível que esse professor possa também ser o sujeito teorizador de si próprio e de sua experiência. (MORAES, 2004, p. 168)

De acordo com Connelly e Clandinin,

Seres humanos são organismos contadores de histórias, organismos que, individual e socialmente, vivemos vidas relatadas. $\mathrm{O}$ estudo da narrativa, portanto, é o estudo da forma como nós, seres humanos, experimentamos o mundo. Dessa ideia geral se deriva a tese de que a educação é a construção e a reconstrução de histórias pessoais e sociais; tanto os professores como os alunos somos contadores de histórias e também personagens nas histórias dos demais e nas suas próprias (CONNELLY E CLANDININ, 1995, p.II).

Essa é uma justificativa para o uso de narrativas em investigações e pesquisas relacionadas com a formação de professores. Utilizando as narrativas para problematizar a questão apresentada sobre as escolhas pela profissão de professores, reconheci nos textos publicados pelos meus alunos inquietações e críticas que também estiveram presentes no meu processo de formação inicial. Neste contexto, são cerca de vinte anos de história em que a valorização da profissão de professor, por conta dos questionamentos feitos a respeito da decisão pela escolha, pouco mudou.

Os alunos de Didática da Matemática, disciplina em que estudamos o conhecimento, metodologias de ensino e referenciais teóricos sobre prática docente e 
pesquisa educacional, se mostraram inquietos, revelando isso no grupo do Facebook, com o fato de que professores já formados não recomendam sua profissão e, mais do que isso, desdenham-na. Preocupa-me o fato de que esses alunos já acham tão comum a ponto de não se espantarem mais - o fato de receberem tantas críticas por desejarem ser professores. Nas aulas de estágio, momento em que os alunos em formação vão para as escolas de Ensino Fundamental e Médio para reconhecerem o espaço escolar e vivenciarem as experiências de docência, os estagiários se sentem constrangidos ao ouvirem dos professores atuantes, as mesmas críticas relacionadas as escolhas pela profissão e isso fica evidente na leitura das postagens e comentários registrados em seus blogs.

\section{Considerações Finais}

A construção das narrativas pelos alunos, a leitura posterior que eles fizeram delas e as discussões decorrentes ajudaram nas reflexões sobre sua formação inicial de professores e sobre o que esperam da profissão, o que enriqueceu os trabalhos na disciplina de Didática da Matemática e a construção dos rastros de experiência na disciplina de Estágio II. O uso dos blogs e o Facebook foi bastante importante nesse processo, pois ajudou na construção dos laços entre uma discussão e outra. Como todos os alunos já estavam acostumados com uso destas TICs, não houve problemas com a condução metodológica desses recursos.

Para aqueles que se interessam em estudar e pesquisar como os blogs e as redes sociais da internet podem atuar nos processos de ensino e aprendizagem, o grande desafio, tanto teórico quanto metodológico, é verificar que transformações tais fenômenos em rede provocam nos processos de produção de significados em atividades educativas.

Dando aos alunos esses espaços virtuais para que ele pudessem falar e olhar para aquilo que disseram sobre suas experiências como professores em formação, ampliaram-se as possibilidades de discussão crítica que o tema encerra. Cada experiência é única e pessoal, mas, quando foi compartilhada, constituiu também a experiência do outro.

Assim, a narrativa, pode ser entendida também como um processo autoformativo por permitir a criação de espaços onde os alunos envolvidos podem se expressar, relembrar, refletir, compreender, relacionar ideias de sentimentos num movimento que pode nunca antes ter sido mobilizado. Quando o espaço criado é o espaço digital, como no caso de uso de blogs e do Facebook, é ágil e rica a interação considerando que hoje a maioria de nós já está integrada com essas formas de comunicação digital. Sentimo-nos à vontade para expressar e compartilhar ideias, pensamentos e experiência. No caso do trabalho aqui apresentado, conseguimos, em grupo, tirar nossas explicações sobre o que leva uma pessoa a querer ser professor. Explicações essas baseadas no que o grupo sentiu e refletiu sobre o que escreveu nos blogs e no Facebook as quais, concluímos, não são verdades absolutas. Ainda bem.

\section{Referências}

CHENÉ, A. A narrativa de formação e a formação de formadores. In: NÓVOA; FINGER (org.). O método (auto) biográfico e a formação. Lisboa: Ministério da Saúde, 1988. p. 65-77.

CONNELY, F. M.; CLANDININ, D. J. Relatos de experiência e investigação 
narrativa. In: LARROSA, J. (org.). Déjame que te cuente. Barcelona: Laertes, 1995. p.11-59.

MARTINS, F. M. Impressões digitais: cibercultura, comunicação e pensamento contemporâneo. Porto Alegre: Sulina, 2008.

MORAES, A. A. A. Histórias de vida e autoformação de professores: alternativa de investigação do trabalho docente. Pro-Posições, Campinas, v. 15, n. 2 (44), p.165-173, 2004. Disponível em: <http://mail.fae.unicamp.br/ proposicoes/textos/44-artigosmoraesaaa.pdf> Acesso em: 18 mar 2013.

RECUERO, R. Redes Sociais na Internet. Porto Alegre: Sulina, 2009

REIS, P. P. As narrativas na formação na formação de professores e na investigação em educação. Nuances: estudos sobre Educação. Presidente Prudente, ano XIV, v. 15, n. 16, p. 17-34, 2008. Disponível em:

<http://revista.fct.unesp.br/index.php/Nuances/article/viewArticle/174> Acesso em: 18 mar 2013.

ROLDÃO, M. C. As Histórias da Educação - A Função Mediática da Narrativa.

Ensinus, Lisboa, v. 3, p. 25-28, 1995.

Disponível em: <http://ierg.net/GPEI/assets/documents/HistseNarrativa.pdf> Acesso em: 12 mai 2013.

SCHERER-WARREN, I. Redes Sociais na Sociedade de Informação, In: MAIA, R.; SPÍNOLA, M.C.P.S. (orgs.): Mídia, Esfera Pública e Identidades Coletivas. Belo Horizonte: Editora UFMG, 2006.

SOUSA NETO, M. F. O ofício, a oficina e a profissão: reflexões sobre o lugar social do professor. Cad. Cedes, Campinas, v. 25, n. 66, p. 249-259, 2005. Disponível em: <http://www.scielo.br/pdf/ccedes/v25n66/a07v2566.pdf> Acesso em: 25 abr 2013. 